\title{
A Novel Classification of Brain Invasion in Malignant Ethmoidal Tumors and Management Proposal
}

\author{
Joel Caballero-García*, Nélido Gonzáles-Fernández, Pedro Pablo Morales-Hechevarría, \\ Carlos Aparicio-García, Misael López Sánchez, Juvenal Huanca-Amaru
}

National Institute of Oncology and Radiobiology, La Habana, Cuba

Email: ${ }^{*}$ joelcaballero.ns@gmail.com

How to cite this paper: Caballero-García, J., Gonzáles-Fernández, N., Morales-Hechevarría, P.P., Aparicio-García, C., Sánchez, M.L. and Huanca-Amaru, J. (2019) A Novel Classification of Brain Invasion in Malignant Ethmoidal Tumors and Management Proposal. International Journal of Otolaryngology and Head \& Neck Surgery, 8, 151-165.

https://doi.org/10.4236/ijohns.2019.85017

Received: June 17, 2019

Accepted: August 19, 2019

Published: August 22, 2019

Copyright $\odot 2019$ by author(s) and Scientific Research Publishing Inc. This work is licensed under the Creative Commons Attribution International License (CC BY 4.0).

http://creativecommons.org/licenses/by/4.0/

\begin{abstract}
Object: Brain invasion is unusual in patients with paranasal sinuses cancer. Staging systems do not specify brain invasion extension who has an impact in therapeutic strategy and prognosis. Surgical series of this patient treated by endonasal endoscopic approach are scarce. In this paper, a novel classification and surgical strategy is proposed. Methods: A retrospective review of patients with ethmoidal malignant tumors with brain invasion treated at the National Institute of Oncology and Radiobiology from January 2015 to October 2017 by means endonasal endoscopic surgery was performed. All medical records were reviewed for demographics, diagnoses, presentation, endoscopic approach, reconstructive techniques and clinical outcomes. Pattern of brain invasion was classified in five grades. Chi-squared test, ANOVA test and Kaplan-Meier curves were used. Results: Forty-seven patients ( 26 males and 21 females) were registered. Mean age was 52.3 years \pm 27.0 . Only 3 patients presented with neurologic symptoms. Histologic subtypes were squamous cell carcinoma (25 patients), adenocarcinoma (16 patients), and esthesioneuroblastoma (6 patients). Five patients corresponded to Grade I, 39 Grade II and 3 Grade III. The mean surgical time was $351.9 \mathrm{~min}( \pm 45)$. The mean blood loss was $704.5 \mathrm{ml}( \pm 206)$. The mean ICU stay was 1.1 (ranging from 1 to 2 ) days and the hospital stay was 5.3 (ranging from 5 to 7) days. Conclusions: Brain invasion represents a particular therapeutic challenge in patients with malignant nasosinusal tumors. Surgical treatment is possible in some cases, including endonasal endoscopic approach. A stage classification of brain invasion helps to establish an optimal surgical strategy and a prognosis.
\end{abstract}

\section{Keywords}

Sinunasal Cancer, Brain Invasion, Endoscopic Surgery 


\section{Introduction}

Paranasal sinuses cancer (PNC) includes a different tumor type like carcinomas (squamous cell carcinoma, anaplastic carcinoma, transitional cell carcinoma, adenocarcinoma, adenoid cystic carcinoma, lymphoma, melanoma, sarcoma), esthesioneuroblastoma and metastases [1]. Patients are most commonly in the 6th to 8 th decade at the time of presentation. While the common presenting symptoms are nasal obstruction, epistaxis, anosmia and nasal discharge, presentation with symptoms referable to intracranial involvement is unusual [2].

In PNC ethmoid sinus comprises $16 \%$ of the total while the maxillary sinus is the site of predilection in $60 \%$ of tumors. However, there is an ethmoidal extension in most of the patients with advanced tumors [2]. When the tumor arises in or involves the ethmoid sinus, early spread to the dura of the olfactory groove is the rule. However, brain invasion is less common due to the anatomical barrier offered by the dura [3]. Those patients are staging as Grade TIVb (very advanced) in TNM classification [4].

Staging systems of PNC (like American Joint Committee of Cancer staging) [4] and esthesioneuroblastoma (Dulgerov staging [5] and modified Kadish staging [6]) do not specificity brain invasion extension who has an impact in therapeutic strategy, surgical approach and prognosis. On the other hand, there is only one specific paper relative to endonasal endoscopic approach for ethmoid tumors with brain invasion [7] and reports are limited by a scarce number of patients as a part of general series [8].

\section{Methods}

\subsection{Patient Population}

A retrospective review of patients with ethmoidal malignant tumors with brain invasion treated at the National Institute of Oncology and Radiobiology from January 2015 to Oct. 2016 by means endonasal endoscopic surgery was performed. Inclusion criteria included: prior biopsy that confirmed a malignant sinunasal tumor (except undifferentiated carcinoma or lymphoma); absence of frontal sinus, sphenoidal sinus, orbital apex, soft tissue or hard paladar invasion; image findings suggesting intracranial extension and an anatomopathological confirmation of olfactory bulb or brain invasion. All medical records were reviewed for demographics, diagnoses, presentation, endoscopic approach, reconstructive techniques and clinical outcomes. Pathologic diagnoses included squamous cell carcinoma, adenocarcinoma and esthesioneuroblastoma. Patients with unresecable nodal disease (N3) and metastatic disease at initial presentation (M1) were excluded. Preoperative radiological investigations included brain MRI (Magnetic Resonance Imaging) and paranasal CT (Computed Tomography) scan

Pattern of brain invasion was classified in five grades: grade 0 to V: "surgically feasible" include: grade 0: no brain invasion; grade I: olfactory bulb invasion. This type is frequently observed in olfactory neuroblastoma who spread throw 
olfactory fibers; grade II include tumors with dural erosion and limited brain invasion (straight gyrus); grade III include tumors with straight gyrus invasion with large base; grade IV involve tumors with straight gyrus invasion with narrow base of implantation or extended laterally to medial orbital wall. In this subtype a combined endonasal and supraorbital key hole approach are necessary; Grade V: "non surgically feasible" include tumors extended posterior to tuberculum sellae with optic chiasm invasion, superior to corpus callosum rostrum in sagittal plane or regional brain metastases (Figure 1). Patients with grade 0 (Figures $2(\mathrm{~A})$-(E)) and $\mathrm{V}$ were excluded as patients with distant metastases.

All cases underwent complete head and neck examination including nasoendoscopy and were discussed at a multidisciplinary staff. Patients participated actively in this process so they understood the implications of sinonasalneoplasia with brain invasion and its treatment. Patients had the option to consider alternative approaches, including traditional "open" approaches.

\subsection{Endoscopic Equipment and Instruments}

A 0-degree straight endoscope, $4 \mathrm{~mm}$ in diameter and $18 \mathrm{~cm}$ in length (Karl Storz Endoscopy, Tuttlingen, Germany) were used during the whole surgical procedure. Angled endoscope $\left(30^{\circ}\right)$ were employed in order to obtain a better view of anterior cranial base and the proper removal of the oncological margins (Draft III procedure, medial orbital wall and type III maxillary sinusotomy. A digital endoscopic HD video camera and a full High Definition (HD) 16:9 flat monitor (1080p60) and a $300 \mathrm{~W}$ Xenon light source were used during the procedures. A high-speed electric microdrill (Karl Storz Endoscopy, Tuttlingen, Germany) with anlong profile handpiece and diamond burr of small diameter (2 $4 \mathrm{~mm}$ ) was employed for the craniectomy.

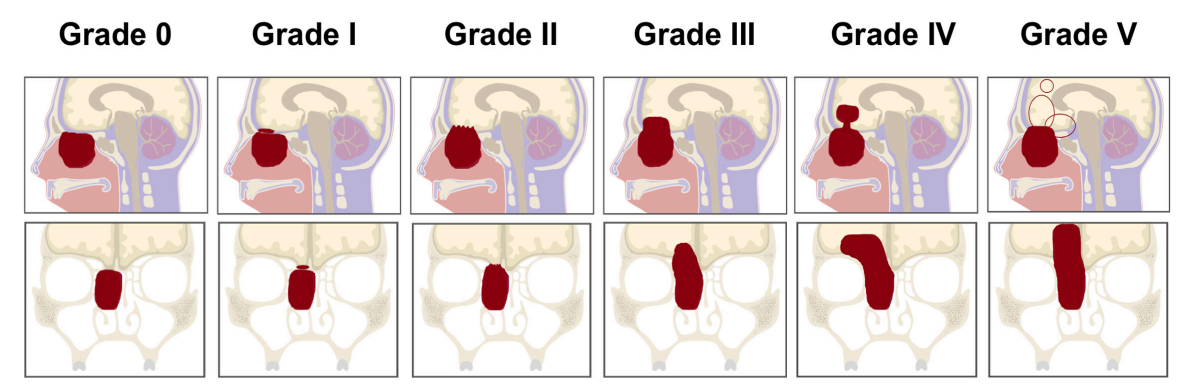

Figure 1. Author's grade system of brain invasion in malignant ethmoidal tumors. Grade 0 to V: "surgically feasible" includes: grade 0 : no brain invasion; grade I: olfactory bulb invasion. This type is frequently in olfactory neuroblastoma who spread throw olfactory fibers; grade II include tumors with dural erosion and limited brain invasion (straight gyrus); grade III include tumors with straight gyrus invasion with large base; grade IV involve tumors with straight gyrus invasion with narrow base of implantation or extended laterally to medial orbital wall. In this subtype a combined endonasal and supraorbital key hole approach are necessary; Grade V: "non surgically feasible" include tumors extended posterior to tuberculum sellae with optic chiasm invasion, superior to corpus callosum rostrum in sagittal planeor regional brain metastases. 


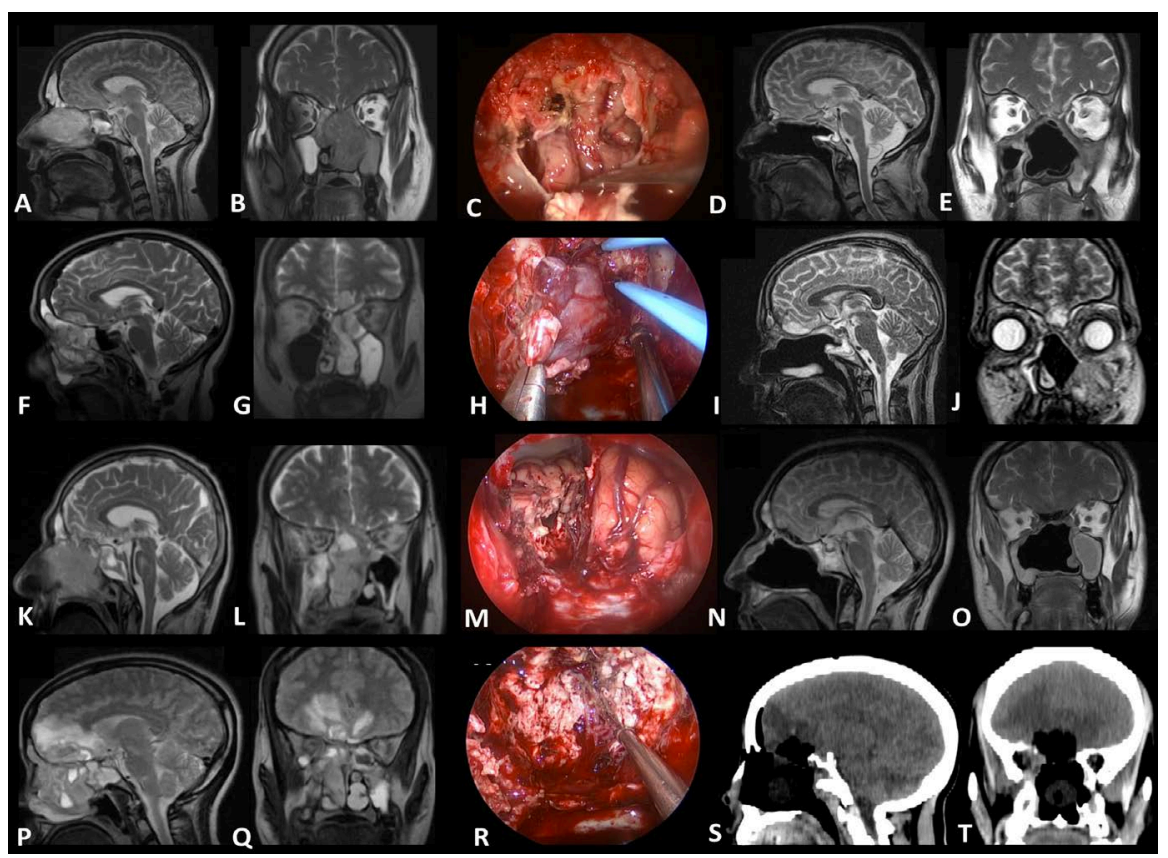

Figure 2. Preoperative studies, surgical images and postoperative studies of patients with different grade of brain invasion. (A)-(E): An example of patient with a squamous cell carcinoma withought brain invasion (grade 0 , not included in this study). (C): Intact olfactory bulbs are shown after anterior cranial base dura removal. (D)-(E): Postoperative MRI showed an intact brain tissue after surgery. (F)-(J): Patient with an esthesioneuroblastoma with left olfactory bulb invasion (grade I). (F)-(G): Preoperative RMI showed absence of brain edema and a hypointense rim surrounded the olfactory bulb enlarged by tumor. $(\mathrm{H})$ : Surgical picture showed the infiltrated olfactory bulb dissection from brain parenquima. (I)-(J): Postoperative MRI showed both olfactory fossa empty before bilateral olfactory bulb resection. (K)-(O): Patient with an squamous cell carcinoma with bilateral limited straight gyrus invasion (grade II). (M): Surgical picture after tumor resection of right straight gyrus. (N)-(O): Postoperative RMI exhibited excellent local control. (P)-(T): Patient with an squamous cell carcinoma with both straight gyrus invasion with large base of implantation (grade III). (P)-(Q): Brain edema was evident in brain invasion. : Surgical picture after total bilateral straight gyrus removal. Both anterior cerebral arteries are exposed after falx lateralization. (S)-(T): Postoperative CT showed the resected zone.

\section{General Surgical Technique}

After orotracheal intubation under general anesthesia, the patient was placed supine with head fixed in the three-point Mayfield-Kees skeletal headrest and turned $10^{\circ}-15^{\circ}$ on the horizontal plane, towards the surgeon. The head was extended 20 degrees to avoid instruments hitting the patient's trunk.

The operative technique for endoscopic resection of anterior cranial base malignancies has been previously described [9] [10]. Nevertheless, authors describe some modifications, especially during the nasal step, the intradural step and the reconstructive step.

\subsection{Preoperative Care}

All patients were administered ceftriaxone via the intravenous route, initiated 
within 1 hour before surgery $(1.5 \mathrm{~g})$ and continued for 5 post-operatively (1.5 g twice a day) until nasal packing (Foley balloon) were removed. Phenytoin were given routinely $(5.7 \mathrm{mk} / \mathrm{kg} /$ day in three subdoses) Standard disinfection procedure and isolation were performed.

\subsection{Surgical Steps}

\subsubsection{Step 1: Nasal Step}

Nasal steps are characterized by two phases: "centrifugal removal" and "centripetal removal" of the tumor. Authors suggest a modification of the technique previously described [9] beginning with an anterior septostomy in order to facilitated a binarial approach using a four hands two surgeons technic, especially in bilateral extended tumors that cause posterior nasal septum invasion. Authors noted that with this maneuver overall blood loss are reduced, due to the fastest and dynamic debulking of the lesion. Centripetal removal of the lesion was carried out until both choanas and sphenoidal rostrum were visible.

Centripetal removal starts with limits of the resection establishment. A wide sphenoidotomy was performing in order to expose the posteroinferior margin of the dissection and to use both optocarotid recess, clival recess and suprasellar notch as landmarks. Then, a Draft III procedure (Lothrop modified procedure) was performed in order to establish the anterosuperior margin of the dissection. Finally, according to the tumor extension, unilateral or bilateral type III maxillary sinusotomy was performed to remove the maxillary component of the tumor, establish the inferolateral margins and helped to identify the papyracea. After that, a subperiosteal dissection of the naso-ethmoidal-sphenoidal complex was performed bilaterally to expose their lateral margins. The periorbita limited the tumor extension and in some cases it was removed in order to obtain better oncological margins. The bilateral ethmoid roof exposure with removal of bony partitions was completed using a drill with a diamond burr. The anterior and posterior ethmoidal arteries were exposed, cauterized with bipolar electric forceps, and dissected. The crista galli was carefully detached from the dura mater and removed with blunt instruments. Then, the dura mater was incised and circumferentially cutting with a falciform scalpel at a safe distance from the suspected area of tumor spread. The falxcerebri was sectioned in an anterior-posterior way at the level of the spheno-ethmoidalplanum.

\subsubsection{Step 2: Intradural Step}

This step is dependent of authors classification according to brain invasion. In "grade I" invasion infiltrated olfactory bulb was removed from brain parenquima by standard microsurgical technique using bipolar cauterization, blunt and sharp dissection. Olfactory tract was cutting as far as possible, usually at the level of posterior limit of sphenoidal planum (Figures $2(\mathrm{G})-(\mathrm{K})$ ). In "grade II" invasion a partial resection of straight gyrus was performed until a normal brain tissue was observed. In grade III invasion more extended resection was necessary. After circumferential piamatter cauterization and sharp section (at the level of 
bone defect), the straight gyrus was removed in an "in block" fashion. Those maneuvers can be unilateral or bilateral according to tumor extension. Frontoorbital artery need to sacrifice withought complications in most of these patients. The posterior limit was the anterior cerebral arteries. Authors use the posterior free edge of falx as a surgical landmark for these vessels. Grade IV invasion was not observed in this series.

\subsubsection{Step 3: Reconstructive Step}

Authors use intranasal or regional vascularized flaps. In patients with viable nasal septum mucosa (withought tumor invasion) a contralateral posterior pediculatenasoseptal flap was employed (Haddad et al.) [11]. When nasal septum invasion was observed, or tumor nearest make impossible a safe oncological removal, a minimally invasive pericranial flap was performed, with some modifications of the originally technique described by Zanation et al. [12]. Authors used a single $4 \mathrm{~cm}$ incision in alignment with a coronal incision centered in the middle pupil line. Previously a limited hair area was shaved. A $1 \mathrm{~cm}$ horizontal right glabellar incision was performed as previously described until the nasion and lacrimal bones was exposed. An endoscopic dissection of the subgaleal plane was performed using a four hand-two surgeon technic through galeal and glabellar incisions to the level of the right orbital rim. Subgaleal dissection was exended posterior to the coronal plane as far as possible to increase the length of the flap. Using a monopolar with a needle tip curved 90 grades the pericranium was incised beginning with the medial sagittal, lateral sagittal (at the level of superior temporal line) and lastly posterior transversal incision. Them, the pericranial flap were elevated until superior orbital rim carefully in order to do not perforate it. A periosteal elevator introducing through glabellar incision was particularly useful during this step. A horizontal $4 \mathrm{~mm} \times 12 \mathrm{~mm}$ osteotomy was performed at the level of the nasion. A curved ostiumexplorator was used to confirm the communication with nasal cavity and the pericranial flap was transposed using endoscopic visualization and carefully flattened to cover the inlay facial graft. Galeal incision was closed using a 2.0 nylon suture and glabellar incision using a 5.0 chromic suture and nylon 3.0 in an intradermic fashion. A multilayer technique using autologous underlay fat, inlay fascia andvascularized flap was performed supported by two Foley balloons.

All patients were extubated in the operation room and were observed one night in the Intensive Care Unit. Foley catheter was maintained until the fifth day of surgery when it was removed. Lumbar spinal drain and navigation were not used.

Comprehensive pre and postsurgical follow up was carried out by the multidisciplinary surgical team (neurosurgeons-ENT surgeons-head and neck surgeons) to evaluate the preoperative status, the healing progress and to avoid any early general and approach-related complications. Postoperatively, an early 24-hours CT scan was used in the immediate follow-up. A standard follow-up 
was done at three months after surgery with MRI initially and then every 6 months.

Patients were undergone multimodality treatment postoperatively. Thus, surgical intervention must be closely coordinated with medical and radiation oncology.

\section{Statistical Analyses}

Statistical analyses were computed using SPSS Version 20.0; Chi-squared test was used to correlate qualitative variables and analysis of variance (ANOVA) test to correlated qualitative with quantitative variables. Items were considered statistically significant with a $\mathrm{p}$ value of less than 0.05 (confidence Interval of 95\%). Kaplan-Meier curves were employed to performed survival analysis and long-rank-test to compare the survival times of the groups.

\section{Results}

Over a 3 year period, a total of 114 endonasal endoscopic approaches for malignant nasosinusal tumors were performed. From them, 47 patients (41\%) presented any grade of brain invasion who conformed the sample. The series consisted of 26 males and 21 females, aged from 20 to 71 years (median 52.3 years \pm 27.0).

According to invasion grade, 39 patients (83.0\%) have grade II, five (10.6\%) corresponded to grade I and three (6.4\%) to grade III. Twenty nine patients (61.7\%) presented unilateral invasion while 18 (38.3\%) presented bilateral invasion. A correlation of grade of invasion and different variables are summarized in Table 1.

Histologic subtypes were squamous cell carcinoma (25 patients), adenocarcinoma (16 patients), and esthesioneuroblastoma (6 patients).

Clinical presentation was nasal obstruction (all patients), anosmia (26 patients), diplopia (21 patients), headache (20 patients), facial numbness (19 patients) visual loss (14 patients), epistaxis (11 patients) cerebrospinal fluid fistulae (4 patients) and mental disturbances (3 patients).

The incidence or brain edema was observed in $97.6 \%$ of patients with grade II and III. However, none of Grade I patients presented it.

Complete resection of the tumor was achieved in all patients. All patients were extubated at the operation room. Surgical margins studies were negatives in all cases including the brain tissue and dura.

Reconstruction methods included minimally invasive pericranial flap in 41 patients and nasoseptal flap in 6 patients.

The mean surgical time was $351.9 \mathrm{~min}( \pm 45)$. The mean blood loss was 704.5 $\mathrm{ml}( \pm 206)$. The mean ICU stay was 1.1 (ranging from 1 to 2 ) days and the hospital stay was 5.3 (ranging from 5 to 7 ) days.

All patients undergo post-op radiotherapy during the first 4 weeks after treatment. 
Table 1. Brain invasion grade according to different variables. National Institute of Oncology and Radiobiology. January 2015 - Oct. 2016.

\begin{tabular}{|c|c|c|c|c|}
\hline \multirow{2}{*}{ Variables } & \multicolumn{3}{|c|}{ Brain invasion grade } & \multirow{2}{*}{$\mathrm{p}$} \\
\hline & Grade I & Grade II & Grade III & \\
\hline \multicolumn{5}{|l|}{ Age group } \\
\hline $20-39$ & 1 & 4 & 1 & \multirow{3}{*}{$0.812^{*}$} \\
\hline $40-59$ & 2 & 23 & 1 & \\
\hline $60-79$ & 2 & 12 & 1 & \\
\hline \multicolumn{5}{|l|}{ Sex } \\
\hline M & 5 & 20 & 1 & \multirow{2}{*}{$0.104^{*}$} \\
\hline $\mathrm{F}$ & - & 19 & 2 & \\
\hline \multicolumn{5}{|l|}{ Histopathology } \\
\hline Squamous cell carcinoma & - & 22 & 3 & \multirow{3}{*}{$0.001^{*}$} \\
\hline Adenocarcinoma & - & 16 & - & \\
\hline Esthesioneuroblastoma & 5 & 1 & - & \\
\hline \multicolumn{5}{|l|}{ Local symptoms } \\
\hline Nasal obstruction & 5 & 39 & 3 & \multirow{4}{*}{$0.687^{*}$} \\
\hline Anosmia & & & & \\
\hline Nasal discharge & 4 & 31 & 1 & \\
\hline Epistaxis & 2 & 5 & - & \\
\hline \multicolumn{5}{|l|}{$\begin{array}{l}\text { Neurological related } \\
\text { symptoms }\end{array}$} \\
\hline Mental disturbances & - & - & 3 & \multirow[t]{2}{*}{$0.001^{*}$} \\
\hline None & 5 & 39 & - & \\
\hline \multicolumn{5}{|l|}{ Imageology feature } \\
\hline Brain edema & - & 38 & 3 & $0.001^{\star}$ \\
\hline \multicolumn{5}{|l|}{ Complications } \\
\hline Frontopolar artery infarct & - & 2 & 1 & 0.137 \\
\hline \multicolumn{5}{|l|}{ Quantitative variables } \\
\hline Mean surgical time & $354.0( \pm 49.3)$ & $346.9( \pm 45.1)$ & $366.7( \pm 15.3)$ & $0.735^{\star *}$ \\
\hline Mean blood loss & $900.0( \pm 289.4)$ & $682.3( \pm 206.3)$ & $666.7( \pm 230.9)$ & $0.113^{\star *}$ \\
\hline ICU stay & $1.0( \pm 0.0)$ & $1.1( \pm 0.3)$ & $1.7( \pm 0.6)$ & $0.011^{\star *}$ \\
\hline Hospital stay & $5.4( \pm 0.9)$ & $5.3( \pm 0.6)$ & $5.7( \pm 1.2)$ & $0.688^{* *}$ \\
\hline Total & 5 & 39 & 3 & \\
\hline
\end{tabular}

${ }^{*}$ Chi-squared test. CI $95 \%,{ }^{* *}$ Values expressed as the "mean" and "standard mean deviation". ${ }^{* * *}$ ANOVA. CI $95 \%$.

The mean follow-up was 16.9 months (ranging from 2 to 30 months). A frontopolar artery infarct sign in CT scan was found in 3 asymptomatic patients. There were noother major complications in the serie like cerebrospinal fistulae, meningitis, pneumoencephalus, convulsions, hematomas or dead.

The 24 months overall survival was $87.2 \%$. Six patients died before 24 months. 
There was a statistically significative difference between the grade of invasion and the survival (Figure 3) opposed to the histology (Figure 4).

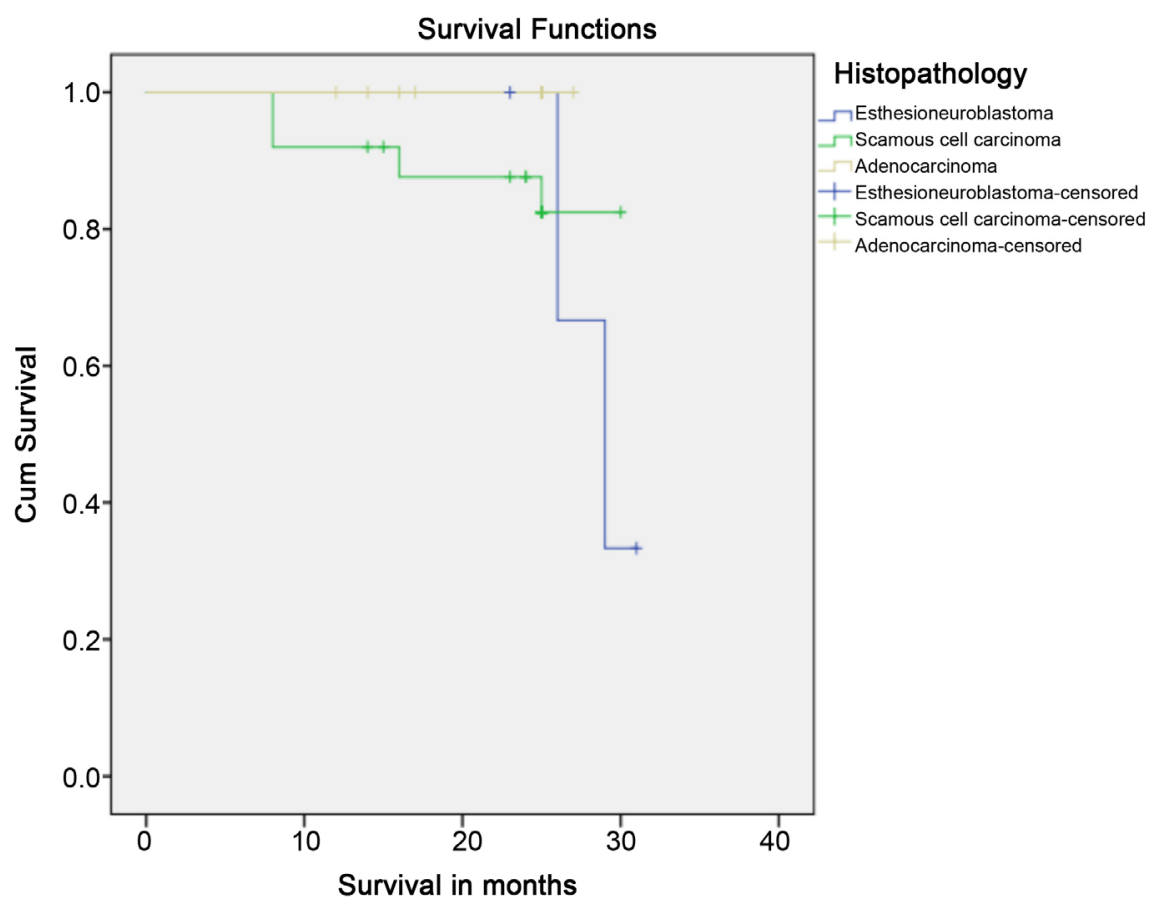

Figure 3. Kaplan-Meier representation of survival following brain invasion grade distribution (Log Rank, $p=0.001$ ). A lower survival rate was founded in grade III patients than grades I and II.

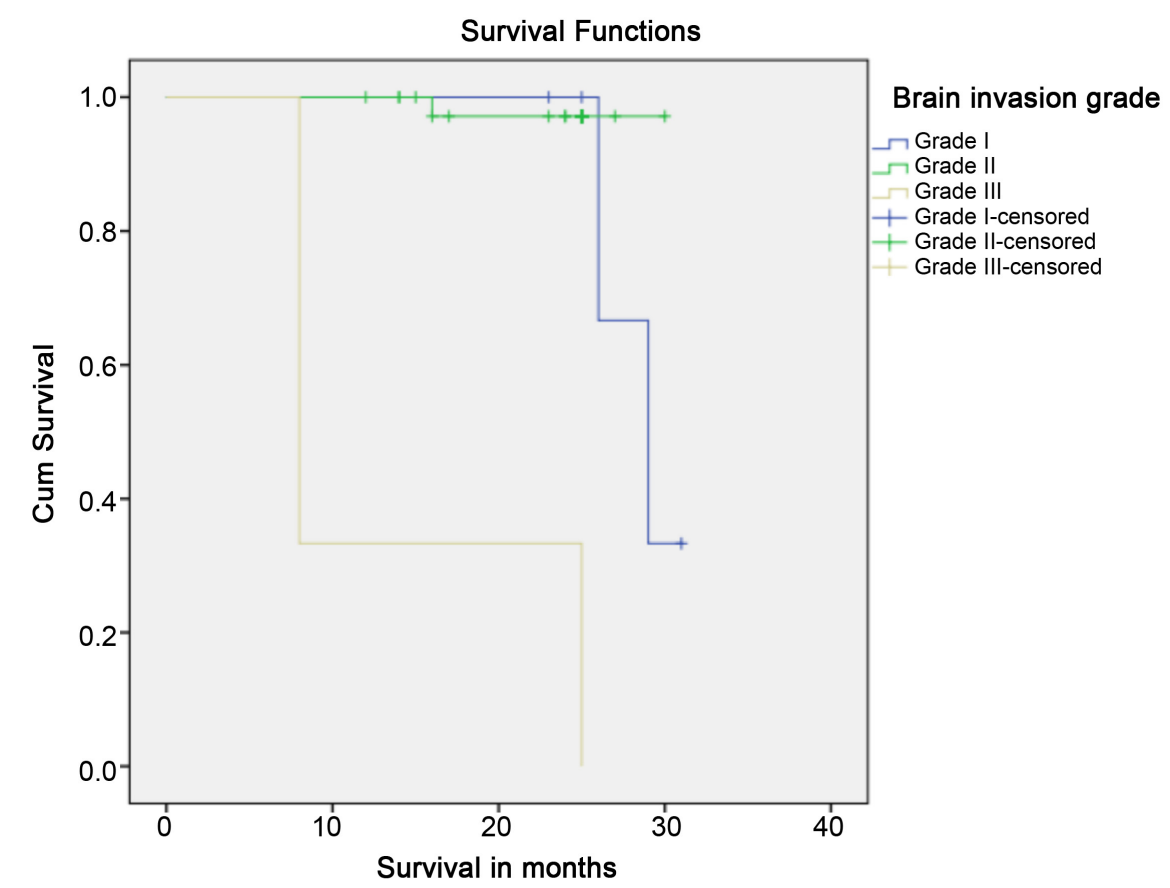

Figure 4. Kaplan-Meier representation of survival following histopathologic distribution (Log Rank, $\mathrm{p}=0.294$ ). There were no significative differences among histological subtypes. 


\section{Discussion}

Sinonasal malignancies account for $0.2 \%-0.8 \%$ of all malignancies and have an incidence of $0.5 \%$ - $1 \%$ per 100,000 per year [13]-[19].

Although first descriptions of a combined transcranial and transfacial approaches were attributed to Walter Dandy (1941) [14] and Ray-McLean (1943) [15] for the resection of invasive orbital tumors, a revision of operative notes of Harvey Cushing documented the craniofacial approaches he applied on 3 patients with anterior skull base involvement as early as 1902-1909 [17]. In 1954 Smith et al. [20] described a combined method of transfacial and transcranial (subfrontal) exposure, for en bloc transfacial tumor removal. Ketcham et al. in 1963 [18] popularized this method. However, most of these approaches are not described in cases with brain invasion who are historically considered a very bad prognostic factor.

\subsection{Particularities of Brain Invasion and Their Management}

Choi et al. [19] in a radiological study founded brain invasion in 6 from 41 patients with malignant head and neck tumors (14.6\%). The low rate of brain invasion observed regarding the malignant nature of these tumors can explain because periorbita and dura act as a temporary barrier and resist tumor expansion, perhaps due to the fibroelastic connective tissue component of these tissues. The high rate of brain invasion observed in author's institution can be explained due some particular factors. First, medical attention of patients with advanced nasosinusal tumors are centralized in this center that receive patients from all country; second, Cuba is a country that combines undeveloped and developed countries facts. There aren't enough diagnostic resources (so early diagnoses is difficult) but, on the other hand, there are adequate therapeutic resources disposable for all patients (free medical attention). Finally, patients with less advances tumors can be treated in other centers by means endonasal endoscopic approaches, so attention with more advances lesions are centralized in our center.

There are two main mechanisms of brain invasion: through olfactory fibers (perineural extension), particulary in esthesioneuroblastoma, and through ACB bone and dura invasion. The easiest access to the intracranial cavity is through the thin osseous floor of the anterior cranial fossa, through the fovea ethmoidalis and the cribriform plate [20]. The foraminal routes to the anterior fossa are through the cribriform plate. The filaolfactoria that penetrate cribiform plate foramina are covered in dura and the bulbs are definite extensions of the brain, thus present a direct route of tumor spread to the brain. Fortunately, the olfactory bulbs are separated from the gyri of the frontal lobes above, and only occasionally will tumor spread to them. This fact supports our advocated classification system.

Presenting symptoms of sinonasal malignant neoplasms typically include nasal obstruction, anosmia, rhinorrhea, epistaxis and facial pain. Actually, in cases 
with brain invasion, Central Nervous System (CNS) relative symptoms are exceptional making early diagnosis necessary to improve the often dismal prognosis [20]. In fact, only patients with more advanced stage of brain invasion (grade III) included in this series developed CNS symptoms (mental disturbances) relatives to brain edema.

A correct clinical evaluation of these patients is necessary to find cervical adenopathy, distal metastases since in this cases aggressive treatment may not cease disease progression and improve survival. Regarding diagnostic studies, although CT scan in brain window (coronal reconstruction) can show brain invasion, edema or local metastases, MRI may show small intracranial deposits and brain edema better than CT. Moreover, CT combined with MRI is a more sensitive tool for the diagnosis of the direct cranial or intracranial extension than CT alone and MRI alone [19]. Authors founded that brain edema was associated with any grade of straight gyrus invasion while patients with only olfactory bulb invasion brain edema was not present. This fact suggests that brain edema should be an indirect sign who indicate straight gyrus invasion and tumor extension beyond olfactory bulb.

In a recent paper, Mattavelli et al. [8] analyzed the results of transnasal endoscopic surgery in selected patients with brain invasion. These interesting article showed the largest series of patients with brain invasion (19 patients operated, 11 with confirmed brain invasion). They founded a very low rate of positive margins in brain tissue and the absence of major complications which are similar results from this study. On the other hand, the hospital stay was equally minimal.

The optimal treatment of this disease remains undetermined due the small number of cases available in the literature. Some authors advocate, when patients are operatively fit with resectable disease, they should undergo aggressive surgical treatment with adjuvant radiotherapy as an attempt to improve outcome due to the fact that radiotherapy alone tends to convey a less favorable outcome, and the role of chemotherapy is unclear [20].

Brain involvement is generally recognized as a poor prognostic factor. Brain invasion is generally considered as a contraindication to pure endonasal endoscopic surgery [3] [4]. On the other hand, craniofacial or cranioendoscopic resections provide more effective identification of the tumor. However, those approaches are associated with higher mortality, morbidity, longer hospitalization, and low life quality [8]. According to the European Position Paper of the European Rhinologic Society [3] brain invasion constitutes an absolute contraindications for endonasal endoscopic approach as an alternative for a transcranial approach. Other authors reinforced that recommendation [15] [21]. Moreover, according to the latest version of the National Comprehensive Cancer Network [22], tumors with brain invasion are considered in a heterogeneous group of very advanced disease and surgery were not recommended. However, clinical data of this study support that even a large mass of intracranial tumor extending superiorly from the olfactory groove has not precluded successful radical resection by 
endonasal endoscopic approach (grade I to III tumors). Nevertheless, there are some cases in which transcranial approach is necessary: if the tumors extended over the orbital floor endonasal endoscopic approach can preclude a total resection. In such cases a classical transcranial approach trough bifrontal craniotomy can be performed but a minimally invasive supraorbital approach can be performed as Barzo et al. [23] described. These authors reported a novel minimally invasive and time-saving combination of supraciliary key hole surgery and the limited facial translocation and recommended it in extensive cases falling out of the indication ow wholly endoscopic surgery and for neurosurgical units in centers with limited patients volume due the long learning curve required to performed an extended endonasal endoscopic surgery. In fact, we suggest that this strategy can be employed in combination with an endonasal endoscopic surgery in patients with more lateral extended lesions that preclude full endonasal endoscopic resection. Moreover, in patients that nasoseptal flap is not possible due tumor extension and a minimally invasive pericranial flap constitute a better reconstructive option, a minimally invasive transglabellar approach could be a better option due the fact that the same glabellar incision employed for pericranial flap can be employed to perform the craniotomy (see picture 3, diagram of authors surgical strategy).

In some cases, multiple intradural nodules of tumor spreading over the anterior cranial fossa floor, or optic nerve and chiasm invasion may prevent curative resection. While in this study, negative surgical margins frozen indicate the suitable oncological removal, a prospective long term follow study should be necessary to obtain more solid conclusions.

\subsection{Oncological Resection and Complications}

In a study performed by Kutlay et al. [21] of endonasal endoscopic approach for different anterior cranial base tumors, gross total resection was achieved in $75.0 \%$ of estesioneuroblastomas and $72.2 \%$ of other sinunasal malignancies. However, the overall cerebrospinal fluid leak was $8.4 \%$. They concluded that despite improved reconstruction techniques, postoperative CSF leakage still remains a challenge. In this study gross total resection was performed in $100 \%$ of patients, regarding brain invasion and none of them presented cerebrospinal fluid leakage, perhaps to use of previously described by Zanation et al. [12] minimally invasive pericranial flap. Excellent results of this reconstructive strategy was previously reported by our group [24].

Remarkable pathologic diversity among ventral skull base malignancies complicates elaboration of a uniform and prognostically relevant staging system. The current American Joint Committee on Cancer TNM staging system [4] is the commonest and widely used. Alternative systems have been proposed for use with individual histopathologic subtypes like Kadish classification in esthesioneuroblastoma [6]. Although there is an empirically knowledge that brain invasion extension can modify the prognosis, none of these systems include brain invasion staging. On the other hand, the staging classification proposed in this 
study can help to surgeons to stablish a surgical strategy. In fact, this study support that staging classification of brain invasion could help to stablish a prognosis due the fact that there were a lower survival in patients with grade III invasion. Further research of this staging system of large international multicenter collaborative studies can contribute with better prognosis comprehension of these tumors. Instead, it seems like in these advanced lesions the histopathology doesn't modify the survival.

The low rate of complications support endonasal endoscopic approach in these advanced tumors. The major complication observed in this series include frontopolar artery infarct which is relative to straight gyrus resection. However, there were not clinical symptoms related and diagnosis was only by imagen.

\section{Conclusion}

Brain invasion represents a particular therapeutic challenge in patients with malignant nasosinusal tumors. There is currently a lack of specific guidelines on their optimal management. Surgical treatment is possible in some cases, including endonasal endoscopic approach. A staging system of brain invasion helps to establish an optimal surgical strategy and prognosis.

\section{Conflicts of Interest}

The authors declare that there are no conflicts of interest regarding the publication of this article.

\section{References}

[1] López, F., Lund, V.J., Suárez, C., Snyderman, C.H., Saba, N.F., Robbins, K.T., et al. (2017) The Impact of Histologic Phenotype in the Treatment of Sinonasal Cancer. Advances in Therapy, 34, 2181-2198. https://doi.org/10.1007/s12325-017-0605-9

[2] Kerawala, C., Clarke, P. and Newbold, K. (2018) Nasal Cavity and Paranasal Sinus Malignancy. In: Scott-Brown's Otorhinolaryngology and Head and Neck Surgery, CRC Press, Boca Raton, 115-134. https://doi.org/10.1201/b15118-205

[3] Lund, V.J., Stammberger, H., Nicolai, P., Castelnuovo, P., Beal, T., Beham, A., et al. (2010) European Position Paper on Endoscopic Management of Tumours of the Nose, Paranasal Sinuses and Skull Base. Rhinology. Supplement, 22, 1-143.

[4] Amin, M.B., Greene, F.L., Edge, S.B., Compton, C.C., Gershenwald, J.E., Brookland, R.K., et al. (2017) The Eight Edition AJCC Cancer Staging Manual: Continuing to Build a Bridge a Population-Based to a More "Personalized" Approach to Cancer Staging. CA: A Cancer Journal for Clinicians, 67, 93-99. https://doi.org/10.3322/caac. 21388

[5] Tajudeen, B., Arshi, A., Suh, J., Palma-Diaz, M., Bergsneider, M., Abemayor, E., et al. (2014) Esthesioneuroblastoma: An Update on the UCLA Experience, 2002-2013. Journal of Neurological Surgery Part B: Skull Base, 76, 43-49. https://doi.org/10.1055/s-0034-1390011

[6] Mehta, G.U., Hanna, E.Y., De Monte, F. and Raza, S.M. (2018) Endoscopic Endonasal Resection of Sinunasal/Anterior Skull Base Malignancy (Kadish C Esthesioneuroblastoma). Acta Neurochirurgica (Wien), 160, 361-366. https://doi.org/10.1007/s00701-017-3437-0 
[7] Kılıç, S., Kılıç, S.S., Baredes, S., Chan, W.P.R., Mahmoud, O., Suh, J.D., et al. (2018) Comparison of Endoscopic and Open Resection of Sinonasal Squamous Cell Carcinoma: A Propensity Score-Matched Analysis of 652 Patients. International Forum of Allergy \& Rhinology, 8, 421-434. https://doi.org/10.1002/alr.22040

[8] Mattavelli, D., Ferrari, M., Bolzoni, V.A., Schreiber, A., Rampinelli, V., Turri-Zanoni, M., et al. (2019) Transnasal Endoscopic Surgery in Selected Nasal-Ethmoidal Cancer with Suspected Brain Invasion: Indications, Technique, and Outcomes. Head \& Neck, 41, 1854-1862. https://doi.org/10.1002/hed.25621

[9] Castelnuovo, P., Battaglia, P., Turri-Zanoni, M., Tomei, G., Locatelli, D., Bignami, M., et al. (2014) Endoscopic Endonasal Surgery for Malignancies of the Anterior Cranial Base. World Neurosurgery, 82, 22-31. https://doi.org/10.1016/j.wneu.2014.07.021

[10] Ray, B.S. and McLean, J.M. (1943) Combined Intracranial and Orbital Operation for Retinoblastoma. Archives of Ophthalmology, 30, 437-445. https://doi.org/10.1001/archopht.1943.00880220029003

[11] Hadad, G., Bassagasteguy, L., Carrau, R.L., Mataza, J., Kassam, A., Snyderman, C.H., et al. (2006) A Novel Reconstructive Technique after Endoscopic Expanded Endonasal Approaches: Vascular Pedicle Nasoseptal Flap. Laryngoscope, 116, 1882-1886. https://doi.org/10.1097/01.mlg.0000234933.37779.e4

[12] Zanation, A.M., Snyderman, C.H., Carrau, R.L., Kassam, A.B., Gardner, P.A. and Prevedello, D.M. (2009) Minimally Invasive Endoscopic Pericranial Flap: A New Method for Endonasal Skull Base Reconstruction. Laryngoscope, 119, 13-18. https://doi.org/10.1002/lary.20022

[13] Dulguerov, P., Jacobsen, M.S., Allal, A.S., Lehmann, W. and Calcaterra, T. (2001) Nasal and Paranasal Sinus Carcinoma: Are We Making Progress? A Series of 220 Patients and a Systematic Review. Cancer, 92, 3012-3029. https://doi.org/10.1002/1097-0142(20011215)92:12<3012::AID-CNCR10131>3.0.C $\underline{\mathrm{O} ; 2-\mathrm{E}}$

[14] Dandy, W.E. (1941) Results Following the Transcranial Operative Attack on Orbital Tumors. Archives of Ophthalmology, 25, 191-216. https://doi.org/10.1001/archopht.1941.00870080015001

[15] Castelnuovo, P., Turri-Zanoni, M., Battaglia, P., Antognoni, P., Bossi, P. and Locatelli, D. (2016) Sinonasal Malignancies of Anterior Skull Base. Otolaryngologic Clinics of North America, 49, 183-200. https://doi.org/10.1016/j.otc.2015.09.012

[16] Mokhtari, S. and Kaley, T.J. (2018) Neurologic Complications of Head and Neck Cancer. In: Cancer Neurology in Clinical Practice, Springer, Cham, 527-539. https://doi.org/10.1053/j.seminoncol.2006.03.007

[17] Pendleton, C., Raza, S.M., Boahene, K.D. and Quinones-Hinojosa, A. (2011) Transfacial Approaches to the Skull Base: The Early Contributions of Harvey Cushing. Skull Base, 21, 207-214. https://doi.org/10.1055/s-0031-1275631

[18] Ketcham, A.S., Wilkins, R.H., Vanburen, J.M. and Smith, R.R. (1963) A Combined Intracranial Facial Approach to the Paranasal Sinuses. The American Journal of Surgery, 106, 698-703. https://doi.org/10.1016/0002-9610(63)90387-8

[19] Choi, H.Y., Yoon, D.Y., Kim, E.S., Baek, S., Lim, K.J., Seo, Y.L., et al. (2018) Diagnostic Performance of CT, MRI, and Their Combined Use for the Assessment of the Direct Cranial or Intracranial Extension of Malignant Head and Neck Tumors. Acta Radiologica, 60, 301-307. https://doi.org/10.1177/0284185118778883

[20] Smith, R.R., Klopp, C.T. and Williams, J.M. (1954) Surgical Treatment of Cancer of the Frontal Sinus and Adjacent Areas. Cancer, 7, 991-994. 
https://doi.org/10.1002/1097-0142(195409)7:5<991::AID-CNCR2820070523>3.0.C $\underline{\mathrm{O} ; 2-\mathrm{P}}$

[21] Kutlay, M., Durmaz, A., Özer, İ., Kural, C., Temiz, Ç., Kaya, S., et al. (2018) Extended Endoscopic Endonasal Approach to the Ventral Skull Base Lesions. Clinical Neurology and Neurosurgery, 1, 129-140.

https://doi.org/10.1016/j.clineuro.2018.02.032

[22] Colevas, A.D., Yom, S.S., Pfister, D.G., Spencer, S., Adelsteim, D., Adkins, D., et al. (2018) NCCN Guidelines Insights: Head and Neck Cancers, Version 1 2018. Journal of the National Comprehensive Cancer Network, 16, 479-490.

https://doi.org/10.6004/jnccn.2018.0026

[23] Barzo, P., Zador, Z., Bodosi, M., Bella, Z., Jambor, D., Fulop, B., et al.(2018) Combined Minimally Invasive Supraciliary and Transfacil Approach for Large Tumors with Skull Base and Sinonasal Involvement. World Neurosurgery, 109, 1-9. https://doi.org/10.1016/j.wneu.2017.08.162

[24] Caballero-Garcia, J., Perez, I.M., Alvarez, A.M.G., Fernandez, N.G., Sanchez, B.R.B. and Pineda, R.B.O. (2018) Minimally Invasive Pericranial Flap for Reconstruction after Endonasal Endoscopic Surgery of 30 Consecutive Patients. Indian Journal of Otolaryngology and Head \& Neck Surgery, 7, 199-208.

https://doi.org/10.4236/ijohns.2018.74021 